\title{
IDOPATHIC PULMONARY HYPERTENSION MIMICKING PULMONARY VENO-OCCLUSIVE DISEASE - A CASE REPORT.
}

\author{
K. Nagendra Prasad, A. Ashok Kumar
}

\begin{abstract}
:
$P V O D$ is rare cause of pulmonary artery hypertension which is associated with worse prognosis and limited treatment options apart from lung transplantation. Differentiating IPAH patients from PVOD is sometimes difficult relying on catheterization data alone. But differentiation between these two diseases is important as there are many evolved treatment options for IPAH. Here we are reporting a case of IPAH where catheterization data shows conflicting results which on further evaluation diagnosis confirmed as idiopathic pulmonary hypertension.
\end{abstract}

\section{INTRODUCTION}

Idiopathic pulmonary arterial hypertension (IPAH) is a rare disorder that can be defined as a sustained elevation in PAP and pulmonary vascular resistance, with normal pulmonary artery wedge pressure, in the absence of a known cause. It is diagnoses of exclusion after other possible causes of PAH have been excluded. It is a severe and often rapidly progressive illness in many cases. We are reporting a case of IPAH in a middle aged female who had features of pulmonary venous occlusive disease (PVOD).

\section{CASE REPORT}

A 35 year old women who is apparently normal 1month before presented with progressive dyspnea on exertion (NYHA class 2), facial puffiness ,bilateral pitting pedal edema ,abdomen distension since 2 wks. There is no history of syncope, chest pain, palpitations, abdomen pain or fever. There is no history suggestive of connective tissue disorders. Patient is married and had 2 children, last child with age of 14 yrs. On examination patient is not anemic. There was no rest or exertional cyanosis. Jugular venous pressure was elevated with

Article received on 5 July 2016, published on 30 July 2016.

K. Nagendra Prasad ${ }^{1}$, A.Ashok Kumar ${ }^{2}$

${ }^{1,2}$ Resident, Department of Cardiology, NIMS, India

Corresponding author: K. Nagendra Prasad,

Email: nagendra.kulari@gmail.com normal lungs. Cardiovascular examination showed severe PAH signs (loud pand parasternal heave of grade3) with prominent tricuspid regurgitation murmur. Oxygen saturation in room air was $92 \%$.

Chest X-Ray showed cardiomegaly with RVH, prominent MPA, right descending pulmonary artery prominence with peripheral pruning, pulmonary congestion, mild right pleural effusion. ECG - right a trial enlargement with right axis of 110 and right ventricular hypertrophy with strain. 2D Echo showed gross right atrial and ventricular dilation, mild TR, moderate PAH (estimated RVSP-50 mm Hg), mild RV dysfunction, good LV function. Lab investigations showed hemoglobin of $11.2 \mathrm{gm} / \mathrm{dl}$, total leukocyte count of 15000 cell/cu.mm, platelet count of $2.6 \mathrm{~L} / \mathrm{dl}$ and with normal ESR, LFT\& renal parameters. Normal thyroid profile was found. No abnormality was detected on ultrasound abdomen. Collagen profile study is negative for anti ds DNA, anti Scl 70, anti SM .Venous Doppler both UL and LL is negative for DVT.

Cardiac catheterization showed mild systemic hypertension (FA-140/70) elevated right ventricular and pulmonary artery systolic pressure (PA-66/21 with mean PAP-50, RV-66/0-2). Left ventricular pressure was normal (LV-110/0-7). Swann Ganz catheter is wedged in right lower pulmonary artery zone. Pulmonary capillary wedge pressure was elevated (PCWP-22). In the absence of left AV valve obstruction we suspected pulmonary venous obstruction in this patient. Saturation data did not reveal any shunt with systemic desaturation (FA So2$75 \%$, PA So2 - 43.6\%).

We did CT pulmonary angiogram (CTPA) to rule out pulmonary thromboembolism and in venous phase to see for pulmonary venous obstruction. It showed evidence of PAH with cardiomegaly,no evidence of acute or chronic PTE. Venous phase study Images were obtained during a single breath hold at full inspiration, with the following parameters: collimation, $2.5 \mathrm{~mm}$; 
table speed, $15 \mathrm{~mm}$ per rotation. Images were reconstructed at $1.0-\mathrm{mm}$ intervals. A total of $150 \mathrm{~mL}$ of non-iodinated contrast material was administered by means of a power injector at a rate of $4 \mathrm{~mL} / \mathrm{sec}$ through an 18- or 20-gauge catheter in an antecubital vein; scanning commenced after a 20-25-second delay.It doesnot showed any major pulmonary venous obstruction. The pulmonary vein diameters at the ostia were : right superior - $11 \mathrm{~mm}$; left superior- $9.6 \mathrm{~mm}$; right inferior- $12 \mathrm{~mm}$; and left inferior- $9.0 \mathrm{~mm}$ which indicates normal. With this available reports patient is diagnosed as Idiopathic pulmonary hypertension. Patient is kept on pulmonary vasodilators, endothelin receptor antagonists, diuretics. Patient improved symptomatically.

Fig 1 : CTPA image showing grossly dilated main, right and left pulmonary arteries.

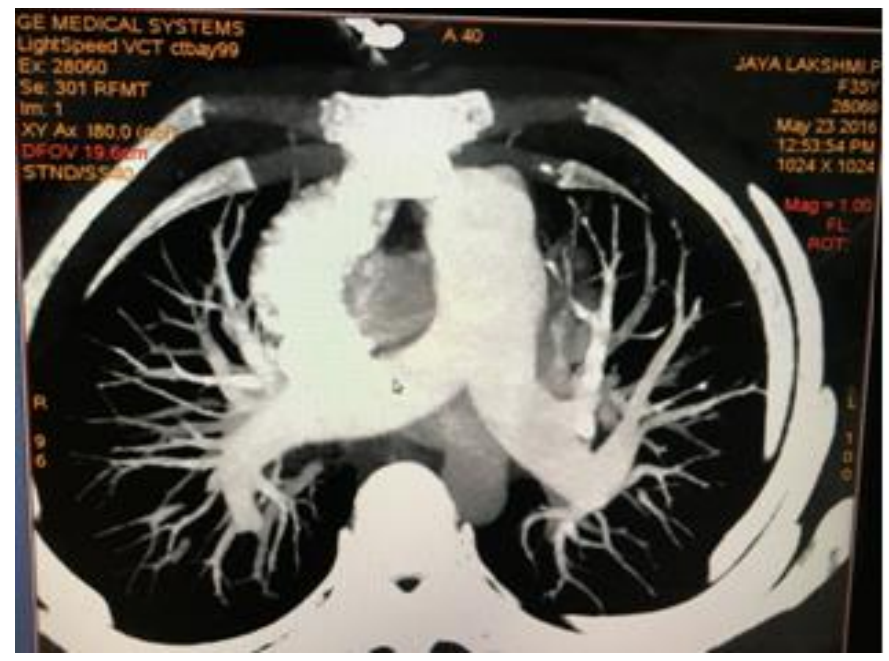

Fig $2: 3 \mathrm{D}$ reconstructed image of pulmonary veins and their branches.

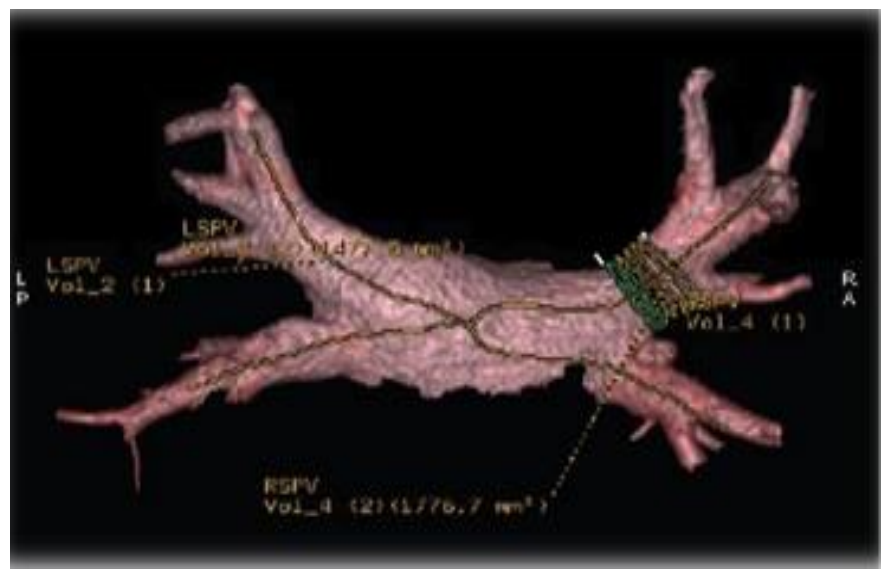

Fig 3 : Venous phage image showing non obstructed pulmonary veins.

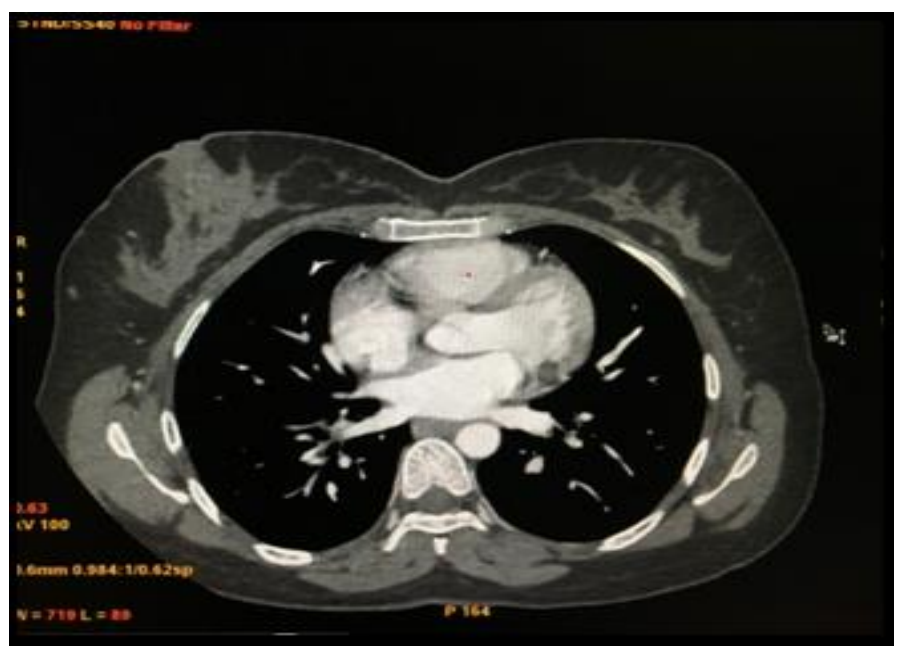

With this available reports patient is diagnosed as Idiopathic pulmonary hypertension. Patient is kept on pulmonary vasodilators, endothelin receptor antagonists, diuretics. Patient improved symptomatically.

\section{DISCUSSION}

Idiopathic pulmonary arterial hypertension is uncommon, representing only a tiny fraction of all cases of pulmonary arterial hypertension. Typically this entity is seen in young women, with diagnosis most frequently made between 20 and 30 years of age[1].Idiopathic PAH is a progressive disorder that usually culminates in right ventricular failure and death. Indifferent small series of PAH studies, the estimated prevalence of PVOD among patients clinically diagnosed with idiopathic $\mathrm{PAH}$ varies from $5-20 \%$ [2]. An Estimate says that $6 \%$ of patients who clinically believed to have primary pulmonary hypertension may have evidence of PVOD at autopsy [3].

In this patient catheterization results favored PVOD. But the CTPA with venous phage imaging doesn't show any evidence of PVOD. Differentiating these two diseases is very important as the treatment and prognosis is different. PVOD is a clinico-pathologic entity characterized by occlusion or narrowing of the pulmonary veins and venules by sometimes loose, sometimes more dense and collagen-rich, fibrous tissue [4] leading to clinical manifestations that are, in many ways, similar to PAH.PVOD, being a post-capillary process, leads to increased visceral pleural and 
pulmonary capillary pressures with transudation of fluid into the pleural space resulting in pleural effusions. Pleural effusions are very rare in patients with primary pulmonary hypertension [5]. Chronic PTE, systolic /diastolic LV dysfunction, left AV valvular diseases, fibrosing mediastinitis, pulmonary capillary hemangiomatosis should be considered in the differential diagnosis of PVOD.

In catheterization test a PCWP of $<15 \mathrm{~mm} \mathrm{Hg}$ ((if catheter is properly wedged) and PVR of $>3 \mathrm{WU}$, mean PA pressure of $>50 \mathrm{mmh}$ goes in favor of PVOD. The central pulmonary veins and the left atrium are not enlarged, in contrast to patients with mitral stenosis, cortriatriatum, or left atrial myxoma [6].The association of ill-defined nodules, septal thickening, and lymphadenopathy should raise the suggestion of a diagnosis of PVOD $[7,8$.$] . Interestingly, a clue to the$ diagnosis of pulmonary veno-occlusive disease is the inability to accurately measure the wedge pressure during cardiac catheterization. Multiple wedge pressure measurements or a distal wedge reading confirmed by a partial pressure of oxygen similar to arterial blood should be performed to determine the correct wedge pressure.

A correctly performed pulmonary capillary wedge pressure measurement generally reveals normal or decreased wedge pressure, despite the fact that the pulmonary capillary pressures (in the absence of a static blood column) are elevated. Occasionally, as in this case an elevated wedge pressure may be obtained, depending on the degree of venous occlusion and collaterals. This may occur because of the patency of the larger pulmonary veins [9].so proper recording of PCWP in different positions will give the correct values. The development of pulmonary edema in response to a pulmonary vasodilator, therefore, is strongly suggestive of the diagnosis of PVOD [10].

A surgical lung biopsy in patients with suspected pulmonary veno-occlusive disease (PVOD) carries a serious risk of morbidity and mortality, particularly in the setting of high pulmonary vascular pressure [11]. Moreover, the results of the biopsy rarely affect PVOD treatment.

The prognosis in PVOD is bad. Most patients have a rapidly progressive course with most reported patients dying within two years of diagnosis without proper treatment $[12,13]$. Currently available PAH therapies do not appear to have a profound effect on survival in patients with PVOD. Currently, lung transplantation is the only therapeutic option capable of significantly prolonging and improving the lives of patients with PVOD. So, correct diagnosis of the type of pulmonary arterial hypertension is mandatory for guiding the treatment protocol.

In our case there was elevated PCWP, but the PCWP in different wedge positions was not tried. As already mentioned previously not only we have to see the wedge trace to see whether that pressure display is due to proper wedging along with oxygen saturation estimation, which was not done in this case. This lead to further testing with chest CT scan.

\section{REFERENCES}

1. Randall PA, Heitzman ER, Bull MJ et-al. Pulmonary arterial hypertension: a contemporary review.

Radiographics. 1989;9 (5): 905-27.

2. Wagenvoort CA. Lung biopsy specimens in the evaluation of pulmonary vascular disease. Chest. 1980; 77(5):614-25.

3. Cassart M, Gevenois PA, Kramer M, et al. Pulmonary venoocclusive disease: CT findings before and after single-lung transplantation. AJR Am J Roentgenol. 1993; 160(4):759-60

4. Wagenvoort CA. Pulmonary veno-occlusive disease. Entity or syndrome?. Chest.1976;69(1):82-6.

5. Dufour B, Maitre S, Humbert M, et al. High-resolution $\mathrm{CT}$ of the chest in four patients with pulmonary capillary hemangiomatosis or pulmonary veno-occlusive disease. AJR Am J Roentgenol. 1998;171(5):1321-4.

6. Swensen SJ, Tashjian JH, Myers JL, et al. Pulmonary veno-occlusive disease: CT findings in eight patients. AJR Am J Roentgenol. 1996;167(4):937-40.

7. Resten A, Maitre S, Capron F, et al. [Pulmonary hypertension: CT findings in pulmonary veno-occlusive disease]. J Radiol. 2003;84(11):1739-45. 
8. Gunther S, Jais X, Maitre $S$ et al. Computed tomography findings of pulmonary veno-occlusive disease in scleroderma patients presenting with precapillary pulmonary hypertension. Arthritis Rheum. 2012;64(9):2995-3005.

9. Mandel J, Mark EJ, Hales CA. Pulmonary veno occlusive disease. Am J RespirCrit Care Med. 2000; 162(5):1964-73.

10. Nicod P, Moser KM. Primary pulmonary hypertension. The risk and benefit of lung biopsy. Circulation. 1989;80 (5):1486-8.
11. Rubin LJ. Primary pulmonary hypertension. N Engl J Med. 1997; 336(2):111-7.

12. Shackelford GD, Sacks EJ, Mullins JD, et al. Pulmonary veno-occlusive disease: case report and review of the literature. AJR Am J Roentgenol. 1977; 128(4):643-8.

13. De Vries TW, Weening JJ, Roorda RJ. Pulmonary veno-occlusive disease: a case report and a review of therapeutic possibilities. Eur Respir J. 1991 Sep;4(8):102932. 